\title{
Leveraging the Capabilities of Online Facilitation as an Interactive Mode of Instructional Delivery in Open and Distance Learning in Nigeria
}

\author{
Adewale Adesina \\ Director, Directorate of Learning Content Management System, National Open University of Nigeria, Plot 91, \\ Cadastral Zone, Jabi, Abuja, Nigeria
}

\begin{abstract}
The need to bridge the instructional gap that exists between teachers and their learners in open and distance learning (ODL) has been widely acknowledged in literature. Scholars have advocated for instructional delivery channels that will facilitate interaction and engagement in the system. Online facilitation remains a crucial component of ODL as it allows seamless interaction between lecturers and students anytime, anywhere. However, this mode of instructional delivery could be hindered by some teacher-related factors, as facilitators have strategic roles to play in content development and delivery. This study was, therefore, carried out to investigate the impact of perceived usefulness and perceived ease of use on facilitators' acceptance of online facilitation in the ODL system of education. The study adopted mixed method research design. A total of 55 facilitators participated in the study and web-based survey was used to collect quantitative and qualitative data from the respondents. The result revealed that the level of acceptance of online facilitation among lecturers was high, with the weighted average of 4.3. The level of lecturers' perceived ease of use and perceived usefulness were also high with weighted averages of 3.9 and 4.3 respectively. There was a significant impact of perceived ease of use on lecturers' level of acceptance of online facilitation as a veritable channel for instructional delivery. Based on these findings, it was therefore recommended that stakeholders in open and distance learning should provide relevant instructional and infrastructural resources to promote effective integration of synchronous and asynchronous online facilitation to engender active participation of students in the teaching-learning process.
\end{abstract}

Keywords: Perceived ease of use, perceived usefulness, instructional gap, online interaction, instructional delivery, online learning

DOI: $10.7176 / \mathrm{JEP} / 11-36-12$

Publication date: December $31^{\text {st }} 2020$

\section{Introduction}

The exponential growth in the number of students seeking admission into higher level of education has necessitated the need for open and distance learning (ODL) institutions to leverage the capabilities of technology, with a view to creating a community of learners that would be able to interact among themselves and with their tutors. This could be achieved regardless of the temporal and spatial gaps among the critical elements within instructional process. Scholars are consistently advocating for the need to encourage active interaction among the key elements in the ODL instructional process (facilitators, students and learning resources), as this would engender collaborative, supportive and positive learning experience among the students (Liu, Magjuka, Bonk, \& Lee, 2007; Palloff \& Pratt, 2007; Hew, 2015, Adedoja, \& Abimbade, 2016). The fundamental challenges of isolation, separation and instructional gaps could easily be surmounted with systematic integration of technology into the ODL instructional process. To adequately bridge this instructional gap, ODL institutions are rapidly taking advantage of the power of technology to create a learning ecosystem that approximates as close as possible to the learning space obtainable in the face-to-face mode of instruction.

\section{Bridging the Instructional Gaps in ODL through Effective Online Facilitation}

It has been established that online facilitation strengthens the relationship among the learners and between learners and their tutors. Online facilitation is an ODL instructional delivery medium that requires competent personnel with appropriate skills and suitable attitude to moderate teaching-learning process in virtual learning environments (Motladi, 2014). An online facilitator is an expert saddled with the responsibilities to galvanise available learning resources to stimulate interaction with the learners and support their learning process, as they take part in online instruction (Goga, 2010). Apparently, online facilitation remains a positive response to meet the needs and aspirations of the ever-increasing population of $21^{\text {st }}$ Century distance learners, who live in media-saturated environments. Online facilitation is increasingly creating a pedagogical shift in the mode of engaging learners in open and distance learning, with focus on interaction, collaboration, and discussion within online learning space. This engenders a paradigm shift in the roles of ODL lecturer from being a custodian of knowledge to a facilitator and collaborative partner, where distance learners become co-constructors of knowledge within instructional setting. In essence, online facilitation creates an online learning platform that establishes new learning environment 
and provides multidimensional learning possibilities (Tuquero, 2011, Esobi, Lasode, \& Barriguete, 2020).). The impact of online facilitation in enhancing ODL instruction has been well established in different parts of the globe. So (2012) investigated the learning outcomes of 25 pre-service teachers in an online video-based learning community and the findings showed that participants gained immensely from peer interaction, self-reflection and collaborative opportunities provided by online facilitation.

However, the possibilities provided by online facilitation have not been properly examined in this part of the world, especially in Nigeria. Like many countries in Africa, online facilitation in Nigeria is evolving with many ODL institutions gradually putting facilities in place to connect students and tutors in virtual learning environment. As the pioneer single-mode ODL institution in the country, the National Open University of Nigeria remains the trailblazer in the provision of accessible, credible and affordable learning opportunities at the higher level of education. As part of the effort to engender flexible and interactive learning content, the institution recently introduced online facilitation to promote interaction and collaboration among the students and between distance learners and their facilitators. The idea was to create a learning community, where students could be afforded the opportunity to interact seamlessly with their counterparts across the globe as well as their facilitators. This has strengthened the existing relationship among the critical elements in instructional process.

Different studies have focused on the instructional benefits derivable from the use of online facilitation for instructional delivery in ODL system of education. However, what remains unclear within Nigerian ODL system is the level of acceptance of online facilitation and factors that could influence the decision of the facilitators to accept and utilize it, as a flexible, engaging, and interactive medium of instructional delivery. With the instructional role in online settings becoming increasingly important, there is a need for studies that focus on the roles of facilitators and factors that could motivate ODL lecturers to participate effectively in online facilitation process (Wallace, 2003). Facilitators remain the key component of online facilitation and it is imperative to examine factors that could determine their level of acceptance of this technology-mediated delivery platform.

An online facilitation environment requires the facilitators to possess a diverse and variety of competencies to take up multidimensional tasks. For instance, facilitators have primary responsibilities of guiding learning, supporting, and assessing students' tasks, providing technical assistance when necessary, interacting with students, facilitating discussion, and providing feedback on student performance at any time (Denis, Angeli, Valanides \& Bonk, 2003; Lentell, 2003; Esobi, Lasode, Anyanwu, Degbe, Flores Barriguete, Okorie, Lasode, \& Okegbe, 2020). These competencies involve interaction with the students, sharing relevant materials with students and ability to properly guide students to learn principles, concepts, and skills across different disciplines. Thus, these multidimensional tasks could systematically alter the roles of facilitators in this $21^{\text {st }}$ Century ODL setting. It is, therefore, natural for some facilitators that are used to the traditional mode of facilitation to put up a kind resistance, when issues relating to online facilitation are being considered. Hence, it is important to examine the level of acceptance of this mode of instructional delivery among facilitators, who had just been introduced into the system. It is instructive to note that online facilitation can never be transformative on its own, it requires facilitators/lecturers who have strong believe in its capabilities to engender interaction and improve students' learning outcomes.

\subsection{Lecturers' Acceptance of Online Facilitation}

Despite the high rate of faculty involvement in online education and acquisition of relevant resources to ensure seamless facilitation, the perception and acceptance of lecturers of the capabilities, legitimacy, and learning outcomes of this instructional process have not changed substantially in the last few years (Allen \& Seaman, 2011; Mandernach, Mason, Forrest, \& Hackathorn, 2012). This poor level of acceptance among lecturers could hinder effective online facilitation process in ODL institutions. To effectively measure successful integration of technology into classroom instruction, it is important to find out its level of acceptance by teachers and students while overcoming the digital gap that exists within the instructional process (Gu, Zhu \& Guo, 2013).

Different models had been employed to measure the level of acceptance of technology-mediated process within the learning space. The most widely-adopted model to measure technology acceptance and use is the Technology Acceptance Model (TAM) by Davis (1986). According to the original model, perceived ease of use and perceived usefulness remain powerful predictors of attitude, which have impact on the acceptance on the part of the system users. Perceived usefulness and perceived ease of use had been empirically proven to have direct influence on system use and acceptance of new technology among the users (Sumak, Hericko, \& Pusnik, 2011; Venkatesh \& Davis, 2000; Abimbade, Adedoja, Fakayode, \& Bello, 2019; Adedoja, \& Abimbade, 2016; Abimbade, Akinyemi, Bello, \& Mohammed, 2017).

The hallmark of TAM is that user's acceptance of technology is determined by his/her behavioural intention, which in turn is determined by his/her perceived ease of use and perceived usefulness ( $\mathrm{Wu}, 2009$; Lee, \& Lehto, 2013; Adedoja, \& Abimbade, 2015). For this study, perceived ease of use and perceived usefulness were adapted from TAM model to measure the impact of these variables on the level of acceptance of online facilitation among facilitators at the National Open University of Nigeria. TAM identifies perceived usefulness as the degree at which 
a system user improves in performance after adopting a particular technology or system (Abimbade, Bello, \& Esobi, 2020; Davies, 1989). In order words, perceived usefulness is the conviction a user placed on a particular technology to assist in achieving organizational/instructional goals or discharging specific responsibilities. In this context, perceived usefulness is the perception a facilitator has about the capabilities of online facilitation to improve interaction and collaboration within the learning space. In the same vein, perceived ease of use, in the words of Davis, is users' perception of the ease of adopting a system or technology. Thus, perceived ease of use can be referred to as the perception of online facilitator about the possibility of using online facilitation with little or no stress. The two factors could influence the rate of acceptance of this instructional delivery mode among the lecturers. Applying this model to e-learning mode of instructional delivery, Pituch \& Lee (2006) argue that the more lecturers' perceive usefulness and ease of use of courses delivering media improve, the more positive their attitudes toward e-learning, which consequently increases their rate of acceptance of the medium.

To effectively examine the extent of acceptance among Nigerian online facilitators, the items in perceived ease of use and perceived usefulness were enriched with relevant exogenous items that are appropriate to measure online facilitation process in NOUN. This could provide a framework for the stakeholders to understand some of the factors that could hinder effective online facilitation in the context of open and distance learning in Nigeria. This study was, therefore, carried out to examine the impact of perceived ease of use and perceived usefulness on facilitators' acceptance of online facilitation as an instructional delivery mode.

\subsection{Research Questions}

i. What is the level of acceptance of online facilitation as a medium of instructional delivery by lecturers at the National Open University of Nigeria?

ii. What is the extent of lecturers' perceived ease of use of online facilitation as an interactive medium of instructional delivery?

iii. What is the level of lecturers' perceived usefulness of online facilitation as a medium of instructional delivery?

iv. Does lecturers' perceived ease of use have any impact on their acceptance of online facilitation as a medium of instructional delivery?

v. What is the effect of lecturers' perceived usefulness on their acceptance of online facilitation as a medium of instructional delivery in NOUN?

vi. What are the perspectives of facilitators on the instructional benefits of online facilitation at the National Open University of Nigeria?

vii. What are the challenges hindering effective use of online facilitation platform by facilitators at the National Open University of Nigeria?

\section{Methodology}

\subsection{Research Design}

This study adopted a mixed method research design to examine the impact of perceived ease of use and perceived usefulness on facilitators' acceptance of online facilitation. Web-based survey was used to generate data for the study. Quantitative data was generated from questionnaire while online interview guide was used to obtain qualitative data from facilitators across all the faculties in the university.

\subsection{Sample and Sampling Technique}

All the lecturers across the faculties form the total population for the study. From this total population, some facilitators were purposively selected to participate in the study. Criteria for the purposive selection include:

1. The facilitators must have participated in the mandatory one week practical training in online facilitation organized for internal and external facilitators. This hands-on training was meant to expose facilitators to the rudiments of online facilitation.

2. Only facilitators who participated in the 6-weeks facilitation sessions were selected for the exercise.

3. Lecturers who teach general and fundamental courses were selected.

Based on these selection criteria, 55 facilitators across the seven faculties were selected to participate in the study. At the end of the exercise, participants were encouraged to respond to the online questionnaire and open-ended interview guide to generate quantitative and qualitative data for the study.

\subsection{Instruments}

The instrument used for the study include questionnaire on acceptance of online facilitation, perceived ease of use and perceived usefulness of online facilitation. Open-ended interview guide on benefits and challenges of using online facilitation in instructional delivery was also used to generate qualitative data.

The questionnaire comprises sections A, B, C, and D. Section A consists of background information of the respondents while Section B comprises thirteen items on acceptance of online facilitation, which measure the 
perspectives and readiness of facilitators to integrate this process into instructional delivery. Sections C and D contain thirteen items each to measure perceived ease of use and perceived usefulness respectively. The questionnaire is measured on 5-Likert type scale of Strongly Agree (SA), Agree (A), Neutral (N), Disagree (D) and Strongly Disagree (SD). The Cronbach coefficient of 0.86 was obtained for the reliability test, which indicated that the instrument was consistently reliable. Interview guide was used to obtain the perspectives of the facilitators concerning the instructional benefits and challenges in using online facilitation to entrench interaction and collaboration in the system.

\subsection{Procedure}

This study was carried out to examine the impact of perceived ease of use and perceived usefulness on facilitators' acceptance of online facilitation. The Directorate of Learning Content Management System (LCMS) manages online facilitation for the National Open University of Nigeria through a platform called "mylearningspace". Before the commencement of the exercise, the directorate organised hands-on training to expose facilitators to the rudiments of synchronous and asynchronous online facilitation procedures. They were also given training manual to subsequently guide them through the process. Their details had previously been captured on zoom database to allow them hold videoconferencing sessions with the students according to the timetable.

Facilitators were able to access the facilitation platform through www.mylearningspace.edu.net to visit their course pages and interact with students across the world as indicated in figure 1. After each synchronous session, the zoom recording link would be posted on the course page for students to watch. This is with the view to ensuring that students who missed the videoconferencing session were not denied of the experience in the virtual classroom session. It is believed that this would encourage self-regulated learning, which is the hallmark of open and distance learning. Lecturers were also encouraged to post 3 questions on discussion forum on the course page, to engage learners asynchronously. Facilitators have the main responsibility of providing feedback to students and weave their submissions to clear misconceptions when necessary.

Students were encouraged to visit their course pages for the facilitation link and join the class or watch videos of previous facilitation sessions. The facilitation sessions lasted six weeks, as each facilitator was allowed to have one hour session per week. This made a maximum of 6 sessions per facilitator. At the end of the exercise, facilitators were encouraged to respond to web-based survey on the level of acceptance, perceived ease of use and perceived usefulness of online facilitation as a medium for instructional delivery. The survey also included openended interview guide that sought to get their perspectives on the instructional benefits and challenges confronting online facilitation in ODL environment.

\subsection{Data Analysis}

The data collected in the study were analysed using mean, median and standard deviation. Analysis of variance (ANOVA) was also used as inferential statistical tool. Qualitative data was content analysed.

\section{Results}

Research Question 1

What is the level of acceptance of online facilitation as a medium of instructional delivery by lecturers at the National Open University of Nigeria?

Table 1: Lecturers' Acceptance of Online Facilitation

\begin{tabular}{|l|l|l|l|}
\hline Faculty & Mean & Median & Standard Deviation \\
\hline Arts & 3.8 & 3.8 & 0.16 \\
\hline Education & 4.5 & 4.5 & 0.34 \\
\hline Health Sciences & 4.3 & 4.3 & 0.34 \\
\hline Law & 4.1 & 4.0 & 0.18 \\
\hline Management Sciences & 4.3 & 4.3 & 0.46 \\
\hline Sciences & 4.6 & 4.6 & 0.29 \\
\hline Social Sciences & 4.7 & 4.8 & 0.13 \\
\hline
\end{tabular}

Weighted Average is 4.3

Table 1 shows the mean score of the facilitators' level of acceptance of online facilitation across all the seven faculties that participated in the study. With the weighted average of 4.3 , the level of acceptance of online facilitation among the lecturers in the institution is well above average. This implies that a good percentage of the lecturers are ready to subsequently adopt online facilitation as a veritable instructional delivery channel in open and distance learning environment.

\section{Research Question 2}

What is the extent of lecturers' perceived ease of use of online facilitation as an interactive medium of instructional delivery? 
Table 2: Lecturers' Perceived Ease of Use of Online Facilitation

\begin{tabular}{|l|l|l|l|}
\hline Faculty & Mean & Median & Standard Deviation \\
\hline Arts & 3.9 & 3.9 & 0.16 \\
\hline Education & 3.8 & 3.9 & 0.84 \\
\hline Health Sciences & 3.8 & 4.0 & 0.39 \\
\hline Law & 3.8 & 3.9 & 0.27 \\
\hline Management Sciences & 3.7 & 3.5 & 0.79 \\
\hline Sciences & 4.4 & 4.4 & 0.17 \\
\hline Social Sciences & 4.2 & 4.1 & 0.51 \\
\hline
\end{tabular}

Weighted Average is 3.9

Table 2 shows the level of perceived ease of use of online facilitation among the lecturers at the National Open University of Nigeria. The weighted average is 3.9, which indicates that the lecturers perceive online facilitation as a friendly, flexible, and easy-to-use instructional delivery channel in online learning environment.

Research Question 3

What is the level of lecturers' perceived usefulness of online facilitation as a medium of instructional delivery?

Table 3: Lecturers' Perceived Usefulness of Online Facilitation

\begin{tabular}{|l|l|l|l|}
\hline Faculty & Mean & Median & Standard Deviation \\
\hline Arts & 3.8 & 3.8 & 0.33 \\
\hline Education & 4.4 & 4.5 & 0.37 \\
\hline Health Sciences & 4.3 & 4.1 & 0.38 \\
\hline Law & 4.2 & 4.1 & 0.38 \\
\hline Management Sciences & 4.4 & 4.3 & 0.54 \\
\hline Sciences & 4.5 & 4.5 & 0.38 \\
\hline Social Sciences & 4.7 & 4.6 & 0.24 \\
\hline
\end{tabular}

Weighted Average is 4.3

Information in table 3 reveals the level of lecturers' perceived usefulness of online facilitation as an appropriate instructional delivery process in the $21^{\text {st }}$ Century open and distance learning space. The weighted average of 4.3 shows that lecturers in the university consider online facilitation as a useful instructional delivery channel that could assist them to interact with their students across the world, with high level of engagement and collaboration. This implies that the participants perceive the synchronous and asynchronous platforms as veritable tools that could afford them the opportunity of discharging their responsibilities more effectively within the learning space.

\section{Research Question 4}

Does lecturers' perceived ease of use have any impact on their acceptance of online facilitation as a medium of instructional delivery?

Table 4: ANOVA of the Impact of Perceived Ease of Use on Acceptance of Online Facilitation

\begin{tabular}{llllll}
\hline Source & DF & Sum of squares & Mean squares & F & P \\
\hline Model & 6 & 1.931 & 0.322 & 2.736 & $\mathbf{0 . 0 2 3}$ \\
Error & 48 & 5.645 & 0.118 & & \\
Corrected Total & 54 & 7.576 & & & \\
\hline
\end{tabular}

\section{Computed against model $Y=\operatorname{Mean}(Y)$}

Table 4 reveals the impact of lecturers' perceived ease of use on their acceptance to participate in online facilitation process. The $p$-value is less than 0.05 level of significance. This indicates that there is a significant effect of lecturers' perceived ease of use on their acceptance of online facilitation as an effective instructional delivery channel in open and distance learning. The implication is that perceived ease of use could be a critical factor determining the acceptance of lecturers to participate in online facilitation process at this level of education.

\section{Research Question 5}

What is the effect of lecturers' perceived usefulness on their acceptance of online facilitation as a medium of instructional delivery in NOUN?

Table 5: ANOVA of the Impact of Perceived Usefulness on Lecturers' Acceptance of Online Facilitation Analysis of variance (Usefulness):

\begin{tabular}{llllll}
\hline Source & DF & Sum of squares & Mean squares & F & P \\
\hline Model & 6 & 1.419 & 0.237 & 1.411 & 0.230 \\
Error & 48 & 8.044 & 0.168 & & \\
Corrected Total & 54 & 9.464 & & & \\
\hline
\end{tabular}

Computed against model $Y=\operatorname{Mean}(Y)$

In table 5, the reveals the impact of lecturers' perceived usefulness on their level of acceptance to participate in online facilitation process. The p-value is greater than 0.05 level of significance. The implication is that 
perceived usefulness has no significant effect on the lecturers' level of acceptance of online facilitation.

\section{Discussion}

The findings from the study revealed that there was a high level of acceptance of online facilitation among lecturers at the National Open University of Nigeria. This implies that the lecturers, who participated in the study, considered online facilitation as an enduring process that should be integrated into the architecture of open and distance learning. This is with a view to engaging distance learners in instructional content, regardless of temporal and spatial barriers within the system. It is noteworthy that the physical separation between lecturer and teacher in open and distance learning has become one of the major criticisms of this system of education. Amid the continued expansion of ODL across different geographical regions of the world, skepticism regarding its quality remains one of the major setbacks in the system. Many scholars are of the opinion that it would be extremely difficult to disseminate quality instruction, with the physical distance among the critical elements of instructional process. Therefore, online facilitation has been considered a strategic platform to bridge these gaps in instructional delivery process. Lecturers who participated in the study might have identified these instructional opportunities provided by online facilitation to engage and interact with students at a distance. This finding is in line with Motladi, (2014) who found that teaching assistants were ready to participate in online facilitation as they already acquired basic computer skills that would promote actively interaction with the students.

The findings also showed that the level of perceived ease of use of online facilitation among participating lecturers was high. The implication is that many lecturers, who participated in the online facilitation intervention, considered the platform as easy channel to engage students in instructional content. It is important to note that online facilitation provides a veritable platform for seamless delivery of instructional content, irrespective of temporal and spatial distance between the lecturer and the students. In order words, online facilitation ensures flexibility in instructional process as lecturer can easily interact with students anytime, anywhere through the learning management system (LMS). This might be responsible for the high level of perceived ease of use among the participants. According to Sumak, Hericko, \& Pusnik, (2011), perceived ease of use remains a critical factor that determines system use and user's participation in technology-related activities.

In the same vein, there was a high level of perceived usefulness of online facilitation as an effective medium of instructional delivery. The finding showed that lecturers believed that online facilitation could assist them to discharge their instructional responsibilities more efficiently in this system of education. This might not be unconnected with the affordances provided by online facilitation to engage learners in instructional content. The synchronous and asynchronous modes of online facilitation allow lecturers to interact actively with the students anytime, anywhere. This allows lecturers to engage students in instructional content and share learning resources with them, regardless of the physical separation. Student can also collaborate with their colleagues to execute instructional tasks. Apparently, online facilitation affords lecturers the opportunity to engage in real teaching that would promote deep learning and active engagement. In a study carried out to develop a general extended technology acceptance model for e-learning, Abdullah \& Ward (2016) found that users' perceived usefulness remains an important factor in technology use.

Findings from research question 4 showed that there was a significant effect of perceived ease of use on lecturers' acceptance of online facilitation as an interactive platform to engage learners at a distance. This means that the way lecturers perceive the intervention as a user-friendly and flexible platform to interact with the students could influence their level of acceptance of online facilitation. This might be due to the fact that users would prefer to adopt a technology or an instructional platform that requires minimum technological competence. Although online facilitation is a technology-based process, it only requires basic computer skills that are indispensable in the $21^{\text {st }}$ Century society. Thus, lecturers with basic technological competence can easily navigate the platform to deliver instructional content and interact with students form diverse background across the world. In the light of this, the perceived ease of use could be a strategic factor that determines the acceptance and participation of lecturers in online facilitation. This finding is corroborated by Nagy, (2018) who affirmed that perceived ease of use had a direct effect on the learning satisfaction in online video usage. Also, Chung, Chen, \& Kuob (2015) reported that perceived ease of use contributed significantly to the behavioural intentions to use mobile English vocabulary learning resources in virtual learning environment.

There was no significant impact of perceived usefulness on lecturers' acceptance of online facilitation as an appropriate instructional delivery mode. This implies that the level of acceptance of online facilitation is not necessarily a function of perceived usefulness. It is noteworthy that technology has pervaded every aspect of human endeavours and it is increasingly becoming difficult to function effectively within the learning space, without basic technology competence. In ODL environment, efforts are being made to galvanise technological resources, with a view to bridging instructional gaps within the learning space. Due to the diverse nature of the distance learners, a wide range of technologies remains a sine qua non to engage all categories of students across the globe. In this wise, distance learning institutions worldwide are providing necessary conditions for lecturers to leverage the capabilities of technological resources to facilitate instructional delivery process. Thus, acceptance of 
these technologies might not necessarily dependent on the perceived usefulness among lecturers. Some institutions might even compel lecturers to participate in online facilitation, regardless of their perception of usefulness of the platform.

In terms of qualitative data, the responses from web-based open-ended interview indicated that lecturers considered online facilitation as a veritable tool to engage learners in instructional content. Some responded that the platform afforded them the opportunity to meet with their students as obtainable in the face-to-face setting. One lecturer remarked that "online facilitation allows facilitators to easily interact with the students in real-time". It is important to note that one of the major setbacks of ODL system of education is the absence of real-time interaction as a result of distance. Synchronous online facilitation allows lecturers to interact with their students in real-time and provide immediate feedback. Some of the respondents also asserted that online facilitation improves online teaching skills of lecturers in ODL setting. One respondent affirmed that "all NOUN Academic staff should be parties to this online facilitation as it improves teaching skills in this learning environment". These positive comments might be due to the affordances provided by online facilitation, with a view to bridging the gap between lecturers and students within the ODL instructional process.

Lastly, reports from the interview suggested that lecturers identified specific challenges confronting effective participation in online facilitation process. Issues like poor internet service, inadequate ICT competence and lack of motivation dominated their discussions. One respondent asserted that "the main challenge to effective online facilitation is poor Internet connectivity across board. This has led to the abrupt disconnection from the Zoom Meetings intermittently and losing time trying to reconnect". This report might not be unconnected with the fact that online facilitation is generally an internet-based teaching-learning process, which requires Internet services for cross-fertilisation of ideas and interaction between the lecturers and students. Thus, any effort at integrating online facilitation in online learning requires effective Internet services for synchronous and asynchronous communications. Another lecturer remarked that "epileptic power supply remains one of the main challenges confronting effective online facilitation in this institution". It is important to note that these instructional and infrastructural challenges could vary across learning institutions worldwide, based on the level of technological development and political will on the part of the management. Apparently, low bandwidth, poor Internet connectivity, cost of providing Internet and erratic power supply had been identified by the lecturers as strategic factors hindering effective online facilitation process in this part of the world. This report is corroborated by GillettSwan (2017) who explains that lecturers and students in ODL require a wide range of resources including computers, webcam, power supply and stable internet connection and the absence of these resources could make simple instructional task like watching a video increasingly complex.

\section{Conclusion}

Online learning is at the threshold of becoming a universally accepted mode of education, especially with the advancement in innovation and technology to bridge the gap between distance learners and their lecturers. Online facilitation entrenches the core values of online learning across different geographical regions of the world. Recognising this fact, the National Open University of Nigeria recently introduced online facilitation to improve engagement and interaction with the students. Apparently, it becomes imperative to investigate likely factors that could determine the level of acceptance of this innovative instructional delivery mode. This study has been able to establish that lecturers consider online facilitation as a useful platform to engage learners in instructional content and interact with diverse categories of students across the globe. Perceived ease of use has also been identified to have a significant impact on the level of acceptance of online facilitation among lecturers in the institution. Therefore, adequate facilities are expected to be provided by major stakeholders in ODL system of education, with a view to surmounting the challenges confronting effective online facilitation at this level of education. To ensure effective online learning, especially at the higher level of education, it is imperative to integrate synchronous and asynchronous online facilitation to engender active participation of students in teaching-learning process. Lastly, instructional, and infrastructural challenges that could hinder effective online facilitation process need to be addressed, especially through provision of stable internet services and regular power supply.

\section{References}

Abdullah, F. \& Ward, R. (2016), "Developing a General Extended Technology Acceptance Model For E-Learning (GETAMEL) by Analysing Commonly Used External Factors", Computers in Human Behaviour 56, 238256.

Abimbade, O., Adedoja, G. O., Fakayode, B \& Bello, L. (2019). Impact of mobile- based mentoring, socioeconomic background and religion on girls' attitude and belief towards antisocial behaviour (ASB). British Journal of Educational Technology (BJET). 50 (2), 638-654. https://doi.org/10.1111/bjet.12719

Abimbade, O., Akinyemi, A., Bello, L., \& Mohammed, H. (2017). Comparative Effects of an Individualized Computer-Based Instruction and a Modified Conventional Strategy on Students' Academic Achievement in Organic Chemistry. Journal of Positive Psychology and Counseling. 1(2). 1-19. 
Abimbade, O., Bello L., \& Esobi, I. C. (2020). Designing a Framework for Training Teachers on Mobile Learning in Sub-Sahara Africa. Journal of Education and Practice. 11(32), 10.7176/JEP/11-32-07

Adedoja G. O., \& Abimbade O. A. (2015). Pre-Service Teachers' Ease of Use and Intention to Use Selected Elearning Technologies in Designing Instruction. American Journal of Educational Research. (3)10, 13201323.http://pubs.sciepub.com/education/3/10/18

Adedoja G. O., \& Abimbade O. A. (2016). Influence of Mobile Learning Training on Pre-Service Social Studies Teachers' Technology and Mobile Phone Self-Efficacies. Journal of Education and Practice, (7)2. 74-79. http://eric.ed.gov/?id=EJ1089740

Adedoja G., \& Abimbade O. (2016). Design and Development of Mobile Learning Lesson Plan (MLLP) Template: A Design Relevant to African Context. American Journal of Educational Research, 4(9). 658-662. doi: 10.12691/education-4-9-2

Allen, I. \& Seaman, J. (2011), “Going the distance: Online education in the United States”. Babson Park, MA: Babson Survey Research Group and Quahog Research Group. Retrieved from http://www.onlinelearningsurvey.com/reports/goingthedistance.pdf

Chung, H., Chen, S. \& Kuob, M. (2015), “A Study of EFL College Students' Acceptance of Mobile Learning”, Procedia - Social and Behavioral Sciences 176, 333 - 339 Available online at www.sciencedirect.com

Davies, D. (1989), "Perceived Usefulness, Perceived Ease of Use, and User Acceptance of Information Technology", MIS Quarterly 13 (3), 319-340.

Dennis, B., Watland, P., Pirotte, S. \& Verday, N. (2004), "Role and Competencies of the E-tutor", Distance Education 9(4), 408-414.

Esobi, I. C., Lasode, M. K. \& Barriguete, M. O. F. (2020). The Impact of COVID-19 on Healthy Eating Habits. Journal of Clinical Nutrition and Health. 1(1). 001 - 002

Esobi, I. C., Lasode, M. K., Anyanwu, C. I., Degbe, E., Barriguete, M. O. F., Okorie, M. A., Lasode, D. O. \& Okegbe, S. (2020). Nutritional Impact of COVID-19 and Its Implications on Atherosclerosis. World Journal of Nutrition and Health, 8(1). 16-21

Gillett-Swan, J. (2017), “The Challenges of Online Learning; Supporting and Engaging the Isolated Learner", Journal of Learning Design 10 (1), 43-56

Goga, M., (2010), "E-competencies of the Tutor in E-learning-A Comparative Study" Proceedings of International Conference on Software, Services \& Semantic Technologies, Sept. 11-12, Varna, Bulgaria, 63-79. https://research.uni-sofia.bg/handle/10506/641 (5p)

Gu, X., Zhu, Y. \& Guo, X (2013), “Meeting the 'digital natives': Understanding the Acceptance of Technology in Classrooms", Educational Technology \& Society 16 (1), 392-402.

Hew, K.F. (2015), "Student Perceptions of Peer versus Instructor Facilitation of Asynchronous Online Discussions: Further Findings from Three Cases", Instructional Science 43, 19-38. https://doi.org/10.1007/s11251-0149329-2.

Lee, D. \& Lehto, M. (2013), "User Acceptance of YouTube for Procedural Learning: An Extension of the Technology Acceptance Model”, Computers \& Education 9, 193-208.

Lee, Y.-H., Hsiao, C. \& Purnomo, S. (2014), “An Empirical Examination of Individual and System Characteristics on Enhancing E-Learning Acceptance”, Australasian Journal of Educational Technology 30(5), 561-579.

Lentell, H. (2003). The Importance of the Tutor in Open and Distance Learning. In A. Tait \& R. Mills (Eds.), Rethinking Learner Support In Distance Education (64-76). London: RoutledgeFalmer.

Liu, X., Magjuka, R., Bonk, C. \& Lee, S. (2007), “Does sense of community matter?" Quarterly Review of Distance Education 8, 9-24.

Mandernach, B., Mason, T., Forrest, K. \& Hackathorn, J. (2012), "Faculty Views on the Appropriateness of Teaching Undergraduate Psychology Courses Online", Teaching of Psychology 39(3), 203-208. doi:10.1177/0098628312450437

Motladi, A. (2014), "Competencies Required for the Facilitation of Online Learning Courses: An Online Teaching Assistants Competency-Based Approach", Mediterranean Journal of Social Sciences 5(23), 56-65 Doi:10.5901/mjss.2014.v5n23p1405

Nagy, J. (2018), "Evaluation of Online Video Usage and Learning Satisfaction: An Extension of the Technology Acceptance Model", International Review of Research in Open and Distributed Learning 19(1), 94-105

Palloff, R. \& Pratt, K. (2007), "Building online learning communities: Effective strategies for the virtual classroom”. San Francisco, CA: John Wiley \& Sons.

Pituch, K. \& Lee, Y. (2006), "The Influence of System Characteristics on E-learning Use", Computers \& Education 47, 222-244.

So, M. (2012), "Quality of Learning Outcomes in an Online Video-Based Learning Community", Asia-Pacific Journal of Teacher Education 40(2), 143-158.

Sumak, B., Hericko, M. \& Pusnik, M. (2011), “A Meta-Analysis of E-Learning Technology Acceptance: The Role of User Types And E-Learning Technology Types”, Computers in Human Behaviour 27, 2067-2077. 
Tuquero, J. (2011), “A Meta-Ethnographic Synthesis of Support Services in Distance Learning Programs”, Journal of Information Technology Education: Innovations in Practice 10, 157-179.

Venkatesh, V. \& Davis, F. (2000), "A Theoretical Extension of the Technology Acceptance Model: Four Longitudinal Field Studies", Management Science 46, 186-204.

Wallace, R. (2003), "Online Learning in Higher Education: A Review of Research on Interactions among Teachers and Students". Education, Communication \& Information 3(2), 241-280. 